PÁGINA ABERTA

\title{
Avaliação do processo de formação do caráter em crianças na Educação Infantil
}

Bruna Rodrigues Cardoso Miranda a Maria Judith Sucupira da Costa Lins ${ }^{b}$

\section{Resumo}

Esse artigo trata da possibilidade de avaliação do início do processo de formação do caráter de crianças na Educação Infantil. A fundamentação teórica está na filosofia de Aristóteles. A hipótese é que a interação social e a vivência das virtudes podem contribuir para essa formação durante as práticas escolares diárias. Os objetivos dessa pesquisa são: promover a aprendizagem e a prática das virtudes amizade, honestidade e justiça; contribuir para a interação social e observar a relação entre a prática das virtudes e o processo de socialização e o início da formação do caráter pelas crianças. A abordagem metodológica foi a pesquisa-ação, com maior comprometimento, por meio de observação, intervenções, oficinas e questionários. Atividades especialmente criadas para essa pesquisa foram selecionadas e apresentadas às crianças. Resultados mostram que é possível avaliar a evolução da aprendizagem e a prática de virtudes nas crianças e que é possível ajudá-las a começar o processo de construção do caráter.

Palavras-chave: Avaliação. Formação do Caráter. Virtudes. Educação Infantil.

\section{Introdução}

Observam-se atualmente dificuldades nas escolas, como também em outras instâncias sociais, referentes a problemas de comportamento ético. A sociedade passa por situações de crise moral, de modo que, hoje, se encontra em Desordem Moral, na expressão cunhada por MacIntyre (2004), exigindo uma reflexão sobre essa questão, e a escola não escapa a essa desordem. Essa realidade leva a uma urgência em se trabalhar o início do desenvolvimento do caráter na infância, um processo contínuo e necessário.

\footnotetext{
a Universidade Federal do Rio de Janeiro, Rio de Janeiro, RJ, Brasil.

b Universidade Federal do Rio de Janeiro, Rio de Janeiro, RJ, Brasil. 
É essencial avaliar, como ensina Lickona (s. d.), quais contribuições a escola pode dar para a formação do caráter das crianças como base complementar à família, e o que pode ser feito para que venha a ser melhorada. Família e escola são instâncias sociais que, paulatinamente, estão sofrendo deterioração, no alerta feito pela filósofa Arendt (1997), o que gera pessoas incapazes de exercerem a cidadania de modo adequado. A escola, além de outras funções, tem o papel crucial de auxiliar na formação do caráter dos alunos, em todos os níveis, sempre em colaboração com a família.

Sabe-se que a formação do caráter é um processo longo, conforme explica Havighurst (1953), multifacetado e sobre o qual variáveis, muitas vezes complexas, interferem. Não se trata de algo simples, que possa ser conseguido por meio do seguimento de um manual de regras. No entanto, há estudos e pesquisas sobre o tema que permitem a avaliação dos procedimentos que estão acontecendo desde o início da formação do caráter. De maneira geral, entende-se que o término da construção do caráter da pessoa deva acontecer no período de vida do jovem adulto, coincidindo com a constituição da personalidade, segundo as pesquisas de Erikson (1987) apontam. A personalidade e o caráter encontram-se em diversos pontos, mas que não cabem ser analisados no momento, por fugirem ao propósito da pesquisa sobre avaliação da formação do caráter inicial em crianças. Ninguém nasce com o caráter determinado, embora haja características naturais (BLOOM, 2014; MARITAIN, 1967) que servem de fundamento. A Educação do caráter precisa ser iniciada desde o nascimento da criança.

É preciso destacar a importância da formação do caráter e pensar quais meios podem ser utilizados para que haja uma ação educativa, auxiliando o processo de seu desenvolvimento. É um grande desafio para a escola avaliar, desde o início da infância, como está ocorrendo essa formação e, por isso, não pode se omitir quanto à participação neste processo. Viver eticamente é uma exigência, tanto pessoal como social, ressalta Hildebrand (1972) e faz parte da vida civilizada. Diante dessa realidade, destaca-se como problema a necessidade de enfatizar a construção do início do processo de formação do caráter da criança na Educação Infantil. Levantou-se a hipótese de que a interação social e a vivência das virtudes podem contribuir para essa formação durante as práticas escolares diárias. A partir de então, foram elaboradas estratégias de avaliação com o intuito de observar como acontece tal formação.

Definir caráter não é das mais fáceis tarefas para o educador. Há desvios de conceituação e uso indevido, popularmente, do termo com diferentes significados. Caráter, segundo Lickona (s. d.), é o desenvolvimento das virtudes, tendo 
como base uma vida com objetivos, produtiva e plena. A partir dessa definição selecionada, encontramos o caminho para essa pesquisa. Na tentativa de melhor compreender a palavra caráter, observemos o que diz Erikson (1976), quanto a esse termo e sua necessária construção:

Os "instintos inatos" do homem são fragmentados de impulsos, aos quais é necessário reunir, dar significado, e organizar durante uma infância prolongada aplicando métodos de Educação e instrução infantis que variam de cultura a cultura e estão determinados pela tradição (p. 85).

O referido autor lembra que uma pessoa não nasce com o caráter definido, pois essa não é uma condição genética.

Caráter é também resultado das interações sociais, conforme aponta Piaget (1973), concluindo pesquisas sobre o desenvolvimento moral de crianças. Para um entendimento mais completo, vejamos a base que se encontra nos estudos de Freud (1997), ao afirmar que a criança nasce com impulsos, tendências e desejos provenientes de sua característica instintiva. Consideramos que esses devem ser organizados segundo uma proposta educativa teleológica, isto é, guiada por fins que são estipulados mediante o conhecimento dos princípios éticos. Sendo a escola uma importante instância social, é compreensível que tenha uma parte significativa no processo de formação (SUCUPIRA LINS; SOUZA, 2018) do caráter de alunos da Educação Infantil.

A socialização é importante, pois o caráter é, a princípio, construído por meio da observação e da imitação, até que seja consolidado. Bartholo (2020, p. 239) diz que a "família é o primeiro ambiente de socialização do bebê e aos poucos vai se expandindo para outros espaços, como creches e pré-escolas", demonstrando a influência dos educadores escolares na vida dos alunos, desde a mais tenra idade. Vale lembrar que a formação do caráter ocorre desde o nascimento da criança, (MONTESSORI, 1967; PIKUNAS, 1976) seja intencional ou não, e de forma sistemática ou assistemática, ou seja, independentemente de ter objetivos claros ou não, a formação acontece.

A criança tende, por natureza, fazer o que lhe é mais agradável, na observação de Sucupira Lins (2004) e busca somente sua satisfação. Diante disso, é de responsabilidade dos pais e educadores encaminhá-la para a socialização e o bem comum, ensinando as virtudes que possibilitam o desenvolvimento do caráter. Aristóteles ensina em seu livro "Ética a Nicômaco" (séc. IV a.C. 2007, livro III, 1119 b12-16) que "a criança deve submeter-se à direção do seu preceptor, também 
o elemento apetitivo deve subordinar-se ao princípio racional", demonstrando a força da criança ser direcionada por alguém capaz de formá-la de maneira positiva.

É preciso que as pessoas envolvidas no ambiente escolar sejam reconhecidas como dignas de serem respeitadas. O desenvolvimento da moralidade está ligado ao desenvolvimento cognitivo e afetivo e às interações sociais estabelecidas ao longo da vida, como detalhadamente mostra Piaget $(1973,1994)$. As interações sociais são básicas e contribuem para o desenvolvimento moral, além de constituírem o relacionamento interpessoal. É na escola que essas acontecem, em primeiro lugar, e de forma bastante marcante.

Uma formação sólida do caráter é de suma importância para que os relacionamentos em sociedade ocorram de maneira harmoniosa, e acontecem por meio de atividades que valorizam os relacionamentos interpessoais. Lickona (2001, s. p.), ao definir a formação do caráter como o desenvolvimento das virtudes, acrescenta que essa é a base para desenvolver "uma sociedade justa, próspera e compassiva", possível de ser alcançada se houver dedicação de todos a fim de desenvolver a prática das virtudes.

Não estamos afirmando que esse processo de formação de caráter foi concluído ao término dessa pesquisa, porque a constituição do caráter, mostrada por Erikson (1987), somente acontece ao término da adolescência. Deste modo, a observação feita na presente pesquisa refere-se exatamente ao início do processo de formação do caráter, pois trabalhamos com um grupo de crianças de cinco e seis anos.

O objetivo aqui estabelecido é identificar o início da formação do caráter por meio da aprendizagem de virtudes e da interação social de uma turma da Educação Infantil de uma escola da rede escolar municipal de Petrópolis.

\section{Avaliação do processo de formação do caráter}

A avaliação, segundo Scriven (2018, p. 29) é "um processo analítico fundamental a todos os empreendimentos intelectuais e práticos disciplinados", que permite identificar a relevância da aplicação de atividades que objetivam o ensino da ética, fundamental para o bem comum. Por meio de atividades diversas desenvolvidas durante a pesquisa, foi possível identificar como acontece a formação do caráter, ainda em sua fase inicial.

Trata-se de uma pesquisa qualitativa, segundo explicam Alves-Mazzotti (1998) e Minayo (2001), que, de acordo com as ciências sociais, é o tipo mais adequado, 
buscando entender a realidade que não pode ser quantificada. Utilizou-se o Método Sucupira Lins (SUCUPIRA LINS, 2015, p. 54), que é um método de pesquisa-ação com maior comprometimento, que expande a possibilidade de "intervenção educativa do pesquisador visando ao bem do pesquisando, pretendendo que as crianças e os adolescentes alcancem, cada vez mais, a perfeição enquanto ser humano", dando ao pesquisador a oportunidade de auxiliar na transformação dos alunos por intermédio da observação e também da ação, de maneira a compartilhar valores e fornecer o desenvolvimento do sujeito. Por meio do método de pesquisa-ação com maior comprometimento, foi possível promover a aprendizagem e a prática das virtudes amizade, honestidade e justiça, e observar elementos da interação social, relacionando a prática das virtudes ao processo de socialização e início da formação do caráter. A responsabilidade do pesquisador é um ponto central no Método Sucupira Lins.

A escola foi escolhida por estar localizada no centro da cidade e por se tratar de uma instituição que recebe alunos de diferentes bairros do município. Tais características propiciaram uma maior diversidade cultural, enriquecendo a coleta de dados para a pesquisa, o que levou a relevantes conclusões.

O grupo de crianças se constituiu de uma turma do quinto período, denominação dada pela instituição para o último ano da Educação Infantil, também denominada Pré-escolar. Ressaltamos que essa faixa etária tem sido foco de pesquisas, pois os pesquisadores perceberam que é importante refletir sobre as possibilidades de desenvolvimento do aluno, desde o início de sua formação, isto é, na Educação Infantil. Ademais, tem se expandido o acesso ao ambiente escolar de alunos nos primeiros anos de vida. A pesquisa realizada por Benavides-Moreno et al. (2019) buscou identificar os principais problemas em relação à qualidade da Educação Pré-escolar no Chile, a fim de propor políticas para o seu aperfeiçoamento. Em outra pesquisa, Bartholo et al. (2020) avaliou o impacto das políticas nas práticas escolares na Pré-escola e nos primeiros anos do Ensino Fundamental no Rio de Janeiro. Tais estudos colaboram significativamente com o desenvolvimento das crianças pequenas e para a preparação e o aperfeiçoamento dos profissionais da área.

Participaram do presente trabalho 19 alunos, na faixa etária de 5 e 6 anos, sendo 10 meninos e nove meninas. Os alunos são representados pelas iniciais dos seus nomes, garantindo o sigilo da identificação e facilitando a organização dos dados.

São alunos provenientes de quatro bairros diferentes da cidade. Levando em consideração a localização por endereço, a diversidade é grande, pois esses 
bairros não se igualam quanto à classe social e cultural. A diversidade é uma característica que enriqueceu a coleta de dados da pesquisa.

A turma é acompanhada por uma professora regente de sala, responsável por desenvolver todo o programa escolar. Vale ressaltar que não havia vínculo anterior entre as pesquisadoras e os alunos observados. Foram avaliadas as atividades das crianças dentro e fora da sala de aula, com o intuito de acompanhar a interação social, segundo a hipótese de que são capazes de auxiliar no início do processo de desenvolvimento do caráter da criança.

Foi realizado todo trâmite legal, tais como a apresentação de documentação exigida pelo Comitê de Ética em Pesquisa, que forneceu o certificado de aprovação; todos os alunos tiveram autorização dos responsáveis para participar da pesquisa e os Termos de Consentimento Livre e Esclarecido foram devidamente assinados. Segundo orientação do Comitê de Ética, o fato de os alunos não serem alfabetizados ainda, levou à não exigência do recolhimento de suas assinaturas.

O objetivo deste artigo é mostrar a avaliação feita no processo de ensino/aprendizagem das virtudes durante o processo de socialização e como ela afeta a formação do caráter das crianças. As virtudes desenvolvidas com os alunos foram: amizade, honestidade e justiça. Outras virtudes poderiam ter sido selecionadas, tanto da obra aristotélica como de autores mais recentes, notadamente Hildebrand (2017), que descreve e analisa de modo claro as que considera principais para o mundo atual. É necessário enfatizar, como insiste Hildebrand (2009), que a pessoa é preciosa e, por isso, há uma exigência da Educação voltada para a construção do caráter de cada uma das crianças.

Observou-se como o aluno se desenvolve com o direcionamento do professor, numa aprendizagem significativa, de acordo com a expressão e com a explanação de Ausubel (1980), que desperta o interesse do aluno. O desenvolvimento, a partir das influências externas advindas da interação social com outras pessoas, sejam funcionários da escola ou outras crianças, também foi avaliado. Importante lembrar que é necessário ao professor ser criativo para que a aprendizagem se torne significativa, conforme ensina Maia e Vieira (2016), principalmente na fase em que se encontram as crianças observadas. Por esse motivo, participaram de 13 oficinas especialmente planejadas para a avaliação realizada.

As atividades das oficinas foram: uma música, uma brincadeira, três histórias, três dramatizações, três dinâmicas, além da elaboração de um sociograma ${ }^{1}$

O sociograma foi proposto por Moreno (1974) como instrumento metodológico para estudar, medir e compreender a rede de relações que se estabelece naturalmente nos grupos. 
(MORENO, 1974), que teve como intuito conhecer os vínculos afetivos entre as crianças. Fichas investigativas foram preenchidas pelos alunos, antes e depois das oficinas, com o objetivo de se obter informações sobre a compreensão que têm a respeito das virtudes trabalhadas e avaliar os possíveis progressos.

Antes e depois da realização das oficinas, aconteceram duas dinâmicas, com conteúdo sobre as virtudes amizade, honestidade e justiça, descritas a seguir.

a) Dinâmica da Justiça e da Amizade - Os alunos foram divididos em duplas e cada dupla recebeu duas caixinhas idênticas: uma contendo doces e a outra vazia. Essa dinâmica teve por objetivo observar se os alunos tinham a capacidade de dividir os doces, por iniciativa própria, com aqueles que receberam a caixinha vazia, identificando assim, se são capazes de agir de forma justa e amiga.

Ao receberem as caixinhas e ouvirem as regras da dinâmica, os alunos foram instruídos a fazer o que quisessem. Foi ressaltado que deveriam esperar para iniciarem a dinâmica juntos, ao comando da pesquisadora. Ao abrirem as caixinhas, alguns alunos que receberam as vazias demonstraram decepção. Um aluno chorou. Perguntamos: "o que vocês podem fazer agora? A aluna JS disse: "dividir!". A pesquisadora respondeu positivamente à ação da aluna. Diante dessa atitude, outros alunos começaram a dividir os doces, fato que enfatiza a exemplaridade, pois, segundo Achtman (2017), os exemplos éticos podem ser um excelente ponto de partida para estudar e ensinar ética. O comportamento de cada aluno está especificado no Quadro 1.

Quadro 1 - Dinâmica da Amizade e Justiça 1

\begin{tabular}{|c|c|c|}
\hline \multicolumn{3}{|c|}{ Dinâmica da Amizade e da Justiça } \\
\hline \multicolumn{2}{|l|}{ Duplas } & \multirow{2}{*}{ Resultado } \\
\hline Caixinha Cheia & Caixinha Vazia & \\
\hline NY & JF & NY teve iniciativa de dividir igual - 3 doces para cada \\
\hline JS & IS & JS teve iniciativa de dividir igual - 3 doces para cada \\
\hline LU & JGU & LU teve iniciativa de dividir igual - 3 doces para cada \\
\hline$A R$ & PE & AR teve iniciativa de dividir igual - 3 doces para cada \\
\hline ME & ALX & ME deu apenas 1 para ALX \\
\hline MN & NA & MN deu 2 para NA \\
\hline MA & $\mathrm{AL}$ & MA quis dividir igual, mas AL quis apenas 1 doce \\
\hline
\end{tabular}

Fonte: Elaboração das autoras (2019). 
As caixinhas continham doces em quantidade par, justamente para facilitar uma divisão justa sem ter que os partir. Nessa dinâmica os alunos tiveram a oportunidade de exercer as virtudes justiça e amizade. Observou-se que as crianças ME e MN tiveram mais dificuldade em dividir os doces que receberam com aqueles que não ganharam nada. AL demonstrou contrariedade ao receber a caixinha vazia: por não ter recebido a caixinha cheia, recusou-se a aceitar os doces que o colega MA insistentemente quis dividir com ela.

Foi realizada novamente essa dinâmica, depois que vivenciaram as virtudes por meio da prática das oficinas. Dessa vez, com o intuito de aumentar a complexidade da dinâmica e incentivar as crianças a dividirem igualmente os doces que receberam, foram colocados em algumas caixinhas cinco doces (e não mais seis, como acontecera na primeira dinâmica).

Dessa dinâmica, participaram 14 crianças, sete receberam as caixinhas cheias e outras sete, vazias. Depois de receberem as caixinhas, tiveram autorização para abri-las e a maioria dos alunos, imediatamente, começou a dividir os doces. Depois de dar dois doces para sua dupla e ficar com outros dois, MA perguntou o que deveria fazer com o doce que sobrou e se poderia jogar no lixo. Respondemos que não precisava jogar fora e perguntamos o que era possível fazer. MA respondeu que poderia dividir e, para isso, bastava partir ao meio o doce - e foi o que fez. Contamos ao grupo o que a aluna MA fez e isso incentivou os demais alunos a fazerem o mesmo.

É possível ver o resultado dessa dinâmica no Quadro 2.

Quadro 2 - Resultado Amizade e Justiça 2

\begin{tabular}{|c|c|c|}
\hline \multicolumn{3}{|c|}{ Dinâmica da Amizade e da Justiça } \\
\hline \multicolumn{3}{|c|}{ Os alunos receberam 5 doces } \\
\hline Pote Cheio & Pote Vazio & Resultado \\
\hline LU & JGA & LU teve iniciativa de dividir igual - $21 / 2$ para cada \\
\hline GU & PE & GU teve iniciativa de dividir igual - $21 / 2$ para cada \\
\hline VO & $\mathrm{JF}$ & VO teve iniciativa de dividir igual $-21 / 2$ para cada \\
\hline YA & LE & YA teve iniciativa de dividir igual - $21 / 2$ para cada \\
\hline MA & ME & MA teve iniciativa de dividir igual - $21 / 2$ para cada \\
\hline AR & NY & AR deu 3 para NY \\
\hline VA & NA & VA deu 2 para NA \\
\hline
\end{tabular}

Fonte: Elaboração das autoras (2019). 
Em seguida, foi dada oportunidade aos que tinham recebido a caixinha vazia de também colocar em prática as virtudes amizade e justiça. Receberam dois doces para que pudessem decidir o que fazer. O resultado pode ser visto no Quadro 3.

Quadro 3 - Segundo resultado Amizade e Justiça 2

\begin{tabular}{|l|c|c|}
\hline \multicolumn{2}{|l|}{ Dinâmica da Amizade e da Justiça } \\
\hline Os alunos receberam 2 doces \\
\hline Recebeu doces & Não recebeu doces & Resultado \\
\hline JGA & LU & JGA teve a iniciativa de dividir igual - 1 para cada \\
\hline PE & GU & PE teve a iniciativa de dividir igual - 1 para cada \\
\hline JF & VO & JF teve a iniciativa de dividir igual - 1 para cada \\
\hline LE & YA & LE teve a iniciativa de dividir igual - 1 para cada \\
\hline NY & AR & NY teve a iniciativa de dividir igual - 1 para cada \\
\hline NA & VA & NA não dividiu \\
\hline ME & MA & ME não dividiu \\
\hline
\end{tabular}

Fonte: Elaboração das autoras (2019).

b) Dinâmica da Honestidade - Colocou-se, na frente das crianças, uma caixa com diferentes brindes, de modo que não era possível visualizá-los. Foram explicadas as regras: 1. Cada criança poderia pegar apenas um brinde e 2 . Somente a própria criança poderia ver o brinde que escolheu para si, não sendo permitido aos colegas e a ninguém mais vê-los. Os nomes foram sorteados para que a escolha fosse justa. Havia 13 crianças na sala e 24 brindes na caixa, logo, deviam sobrar 11 brindes. No entanto, verificou-se que somente nove brindes sobraram: isso corresponde ao déficit de dois brindes, indicando que alguém tirou mais de 1 brinde, não exercitando a virtude honestidade conforme descrito no Quadro 4. Houve trapaça. Não se sabia qual ou quais crianças havia desrespeitado a regra principal, fato exposto posteriormente pela própria criança e que será apresentado mais à frente. Entretanto, a regra número 2 foi respeitada por todos os alunos.

Quadro 4 - Resultado Honestidade 1

\begin{tabular}{|l|c|c|c|c|}
\hline $\begin{array}{l}\text { Brindes } \\
\text { disponíveis }\end{array}$ & $\begin{array}{c}\text { Alunos } \\
\text { participantes }\end{array}$ & $\begin{array}{c}\text { Brindes que deveriam } \\
\text { ter sobrado }\end{array}$ & $\begin{array}{c}\text { Brindes que } \\
\text { sobraram }\end{array}$ & $\begin{array}{c}\text { Déficit de } \\
\text { brindes }\end{array}$ \\
\hline 24 & 13 & 11 & 9 & 2 \\
\hline
\end{tabular}

Fonte: Elaboração dos autoras (2019). 
A dinâmica da Honestidade foi novamente aplicada. Antes de dar início, perguntou-se o que significa essa palavra. GU disse: "é não mentir". A dinâmica dessa virtude, que havia sido feita anteriormente, foi lembrada e perguntou-se aos alunos se obedecer às regras é ser honesto. ME disse: "tia, eu peguei três brinquedos da outra vez que teve a brincadeira". Nova oportunidade foi dada a ME para que obedecesse às regras. Observou-se uma evolução na postura de $\mathrm{ME}$, pois, sem ser perguntado, reconheceu espontaneamente o erro cometido na dinâmica anterior, assumindo a falta de virtude.

Foi ensinado a todos que desobedecer à regra e pegar mais de um brinquedo é não ser honesto. Foram parabenizados os que obedeceram e nova chance foi dada para os outros, que poderiam ganhar, assim, uma recompensa ao final da aula. A dinâmica foi iniciada. Antes, houve um aviso que, para haver justiça, haveria um sorteio dos nomes, a fim de decidir a ordem dos que pegariam os brinquedos.

O resultado da dinâmica está exemplificado no Quadro 5. É possível observar a evolução no resultado final do déficit dos brindes, que foi diminuído.

Quadro 5 - Resultado Honestidade 2

\begin{tabular}{|l|c|c|c|c|}
\hline $\begin{array}{l}\text { Brindes } \\
\text { disponíveis }\end{array}$ & $\begin{array}{c}\text { Alunos } \\
\text { participantes }\end{array}$ & $\begin{array}{c}\text { Brindes que deveriam } \\
\text { ter sobrado }\end{array}$ & $\begin{array}{c}\text { Brindes que } \\
\text { sobraram }\end{array}$ & $\begin{array}{c}\text { Déficit de } \\
\text { brindes }\end{array}$ \\
\hline 30 & 14 & 16 & 15 & 1 \\
\hline
\end{tabular}

Fonte: Elaboração das autoras (2019).

Ao terminar a dinâmica, constatou-se que algum aluno havia pegado dois brindes. As pesquisadoras parabenizaram todos os que obedeceram e deram nova chance ao aluno que descumpriu a regra. ME disse: "tia, fui eu, me desculpe" e devolveu um dos brindes. Ao perceber que o aluno demonstrou interesse em obedecer às regras dadas na dinâmica, mesmo sem as ter respeitado anteriormente, as pesquisadoras disseram ao aluno que ele teria mais uma chance em nova oportunidade.

Realizou-se a Dinâmica da Honestidade, com o objetivo de dar nova oportunidade aos alunos de desenvolverem essa virtude. Um pote de jujubas previamente contadas foi colocado diante dos alunos. Eles poderiam pegar apenas quatro jujubas, sem que ninguém pudesse vê-los. Os que respeitassem a regra ganhariam uma recompensa. Depois que os alunos pegaram as jujubas, constatou-se que todos os alunos respeitaram o que foi pedido. Abaixo o resultado no Quadro 6. 
Quadro 6 - Resultado Honestidade 3

\begin{tabular}{|l|c|c|c|c|}
\hline $\begin{array}{l}\text { Jujubas } \\
\text { disponíveis }\end{array}$ & $\begin{array}{c}\text { Alunos } \\
\text { participantes }\end{array}$ & $\begin{array}{c}\text { Jujubas que deveriam } \\
\text { ter sobrado }\end{array}$ & $\begin{array}{c}\text { Jujubas que } \\
\text { sobraram }\end{array}$ & $\begin{array}{c}\text { Déficit de } \\
\text { jujubas }\end{array}$ \\
\hline 65 & 10 & 25 & 25 & 0 \\
\hline
\end{tabular}

Fonte: Elaboração das autoras (2019).

Houve avanço quanto ao exercício da virtude dos alunos no decorrer das atividades desenvolvidas. Em relação a essa dinâmica, na primeira vez que foi aplicada, houve déficit de dois brindes, na segunda de um brinde e na terceira, e última, o déficit foi zero. Isso mostra ser possível ensinar, por meio da prática, virtudes aos alunos (SUCUPIRA LINS, 2004). A prática das virtudes colabora com o processo de desenvolvimento do caráter da criança, que tem início na primeira infância (ERIKSON, 1976), fase em que estão os alunos pesquisados.

Destaca-se a atitude de ME, que teve inicialmente dificuldade em respeitar as regras. Dessa vez, foi capaz de respeitá-las e demonstrou grande alegria ao receber elogios e, também, uma recompensa por ter sido capaz de vivenciar as virtudes trabalhadas. $\mathrm{O}$ aluno $\mathrm{ME}$ praticou a virtude.

Ao término das atividades, e depois de ter todos os dados coletados, foram feitas análises, por meio de incidências, seguindo o método de Bardin (2010), indicando as palavras que mais apareceram nas descrições feitas pelos alunos ao preencherem as fichas investigativas antes e depois das oficinas. As fichas investigativas consistiram em uma folha na qual as crianças desenharam o que entendiam sobre cada uma das virtudes. Depois dos desenhos, conversou-se individualmente sobre o que haviam desenhado e escreveu-se ao lado seu significado.

Destacam-se nos quadros abaixo as principais palavras mencionadas no preenchimento das fichas investigativas referentes às categorias a priori. A intenção foi avaliar como os alunos entendiam cada uma das virtudes, antes e depois da realização das oficinas. Os quadros apresentam uma comparação das fichas investigativas preenchidas pelos alunos, que visaram ao entendimento e à vivência das virtudes amizade, honestidade e justiça.

Apresenta-se a descrição do Quadro 7 com informações sobre as fichas investigativas da virtude amizade, preenchidas pelos alunos antes do início das oficinas. Participaram do preenchimento dessa ficha investigativa 12 alunos. 
Quadro 7 - Ficha Investigativa A1

\begin{tabular}{|c|c|c|c|}
\hline \multicolumn{4}{|c|}{$\begin{array}{l}\text { Ficha Investigativa A1 } \\
12 \text { crianças }\end{array}$} \\
\hline Brincar & Manifestação de carinho & Afetividade & Não conceituou \\
\hline 7 & 2 & 1 & 2 \\
\hline
\end{tabular}

Fonte: Elaboração das autoras (2019).

Observa-se no Quadro 7 que 58\% das crianças desenharam e apontaram que a virtude amizade está relacionada com brincar, utilizando expressões como "amigos jogando futebol", descrito por GU; também o que disse ME: "duas pessoas brincando de arminha de água". Outros 16\% acreditam que amizade tem relação com a manifestação de carinho. Por exemplo, AT afirmou: "estamos nos abraçando". YA desenhou seu autorretrato junto com a professora da turma, envoltas em corações, o que se aproxima da palavra afetividade. Outras duas crianças não souberam explicar o que haviam desenhado, por isso, esses desenhos não foram conceituados.

O Quadro 8 foi elaborado a partir da coleta de dados dos desenhos e das definições que os alunos apontaram sobre a virtude amizade no preenchimento da ficha investigativa depois da realização das oficinas. Treze alunos participaram. Foi possível avaliar uma significativa mudança, que demonstra ser possível ensinar conceitos de virtudes a crianças nessa idade e elas entenderem. Embora tratem-se de crianças de cinco e seis anos, a avaliação mostrou que foram capazes de aprender conceitos que podem ser considerados complexos, dentro de sua capacidade cognitiva (BRUNER, 1978; PIAGET, 1971), mas que foram vencidos.

Quadro 8 - Ficha Investigativa A2

\begin{tabular}{|c|c|c|c|}
\hline \multicolumn{4}{|c|}{$\begin{array}{l}\text { Ficha Investigativa A2 } \\
13 \text { crianças }\end{array}$} \\
\hline Brincar & Ajudar & Partilhar & Afetividade \\
\hline 6 & 3 & 3 & 1 \\
\hline
\end{tabular}

Fonte: Elaboração das autoras (2019).

Sobre a virtude amizade, Aristóteles (séc. IV a.C. 2007, livro IX, 1167a1-5) afirma que: "a boa vontade parece ser o início da amizade", o que se nota na fala de LE ao descrever uma situação em que há uma disposição de boa vontade de 
um amigo para o outro. Acredita que ser amigo é "um amigo ajudando o outro a levantar", como explicou. Vê-se ainda o filósofo afirmar "numa amizade baseada na virtude, cada uma das partes anseia por beneficiar a outra, uma vez que é isso que caracteriza a virtude e a amizade" (ARISTÓTELES, séc. IV a.C. 2007, livro VIII, 1162b5-10), o que se relaciona com a expressão de JGU ao dizer: "Amigos dividindo o brinquedo". JGU acredita que ser amigo é partilhar o que se tem, ou seja, é uma atitude que visa ao benefício do outro.

Três crianças apontaram que ser amigo é saber partilhar. NA descreve: "amigas dividindo o biscoito". Essas palavras não apareceram nas falas de nenhum aluno antes da realização das oficinas, o que nos leva à avaliação da capacidade de entender os conceitos trabalhados. Sabe-se que "A amizade entre os seres humanos, portanto, requer que estes (a) sintam afeição (boa vontade) recíproca, ou seja, queiram o bem um do outro", segundo (ARISTÓTELES, séc. IV a.C. 2007, livro VIII, 1156a1-5), indicando esse bem-estar relacionado ao ato de ajudar e de partilhar, apontado por $45 \%$ dos alunos.

Foi elaborado também o Quadro 9 sobre honestidade (H1), com a descrição dos conceitos dados sobre essa virtude antes da realização das oficinas sobre esse tema. Treze crianças preencheram a ficha investigativa da virtude honestidade.

Quadro 9 - Ficha Investigativa H1

\begin{tabular}{|c|c|c|c|c|}
\hline \multicolumn{5}{|c|}{$\begin{array}{l}\text { Ficha Investigativa H1 } \\
13 \text { crianças }\end{array}$} \\
\hline Lixo & Afetividade & Pegar & Fazer mal & Não conceituou \\
\hline 9 & 1 & 1 & 1 & 1 \\
\hline
\end{tabular}

Fonte: Elaboração das autoras (2019).

No Quadro 9, observa-se que $70 \%$ dos alunos citaram palavras relacionadas ao lixo como conceito de honestidade. O desenho de GU contém a seguinte descrição: "menino jogando lixo no chão". Os demais citaram as palavras: "afetividade", "pegar" e "fazer mal" como conceito de honestidade. Houve uma criança que não conceituou a palavra e disse claramente que não sabia do que se tratava.

O Quadro $10(\mathrm{H} 2)$ mostra as palavras que foram usadas no preenchimento das fichas investigativas, a partir do entendimento da virtude honestidade depois de terem participado de todas as oficinas. 
Quadro 10 - Ficha Investigativa H2

\begin{tabular}{|l|l|c|}
\hline \multicolumn{3}{|l|}{$\begin{array}{l}\text { Ficha Investigativa H2 } \\
\mathbf{1 4} \text { crianças }\end{array}$} \\
\hline Roubar & Dividir & Brincar \\
\hline 10 & 2 & 2 \\
\hline
\end{tabular}

Fonte: Elaboração das autoras (2019).

Constata-se que depois de aprenderem o conceito da virtude honestidade, por meio das práticas das oficinas, não houve relação dessa virtude com o lixo, como aconteceu no Quadro 10. Nesse momento, 70\% das crianças citaram palavras como: "pegar", "roubar" ou "arrancar", que foram agrupadas à palavra "roubar", descrita no quadro. Destaca-se o entendimento desse conceito, pois essas palavras estão relacionadas com uma atitude honesta ou não. Todos mencionaram essas atitudes como algo que não deve ser feito.

Por último, apresentamos os Quadros 11 e 12 sobre a virtude justiça (J1 e J2). O Quadro 11 (J1) foi organizado com o intuito de entender como conceituam a virtude justiça antes das oficinas que levaram à aprendizagem e à prática da mesma. Catorze crianças participaram do preenchimento dessas fichas.

Quadro 11 - Ficha Investigativa J1

\begin{tabular}{|c|c|c|c|}
\hline \multicolumn{4}{|c|}{$\begin{array}{l}\text { Ficha Investigativa J1 } \\
14 \text { crianças }\end{array}$} \\
\hline Polícia & Confronto & Escola & Cuidado \\
\hline 8 & 4 & 1 & 1 \\
\hline
\end{tabular}

Fonte: Elaboração das autoras (2019).

Observamos no Quadro 11, que 55\% das crianças associaram justiça à palavra "polícia" e 30\% das crianças acreditam que essa virtude está relacionada a confrontos: "um homem atirando dentro do carro", definição dada por JS. Nota-se também a descrição de MA: "cara do bem atirando com uma arma". Essas expressões foram sintetizadas na palavra confronto. Os dois conceitos têm relação semelhante, de modo que é possível observar que $85 \%$ das crianças entendem que justiça está relacionada a práticas de ação policial ou de violência.

O Quadro 12 apresenta os dados que as crianças descreveram ao preencher a ficha investigativa com os conceitos da virtude justiça depois da participação nas oficinas sobre esse tema. 
Quadro 12 - Ficha Investigativa J2

\begin{tabular}{|l|c|c|}
\hline \multicolumn{3}{|l|}{$\begin{array}{l}\text { Ficha Investigativa J2 } \\
11 \text { crianças }\end{array}$} \\
\hline Regra & Partilhar & Brincar \\
\hline 5 & 4 & 2 \\
\hline
\end{tabular}

Fonte: Elaboração dos autores (2019).

Houve mudança significativa dos conceitos apontados pelos alunos depois da realização das oficinas. No Quadro 12, 45\% das crianças desenharam situações para definir justiça envolvendo regras. JGU desenhou uma cena intitulada: "A mãe falou para o filho não jogar papel no chão", que é coerente com o que afirma Aristóteles (séc. IV a.C. 2007): "O justo é, portanto, o respeitador da lei e do probo, e o injusto é o homem sem lei e ímprobo" (séc. IV a.C. livro V, 1129a30). Podemos avaliar que foram capazes de entender justiça relacionada às leis. As crianças mostraram situações nas quais são dadas regras para serem obedecidas.

Dentre os participantes, $40 \%$ acreditam que ser justo é saber partilhar, mostrando entender o conceito aristotélico de justiça. Aristóteles (séc. IV a.C. livro V, 1130 a5) diz: "somente a justiça, entre todas as virtudes, é o bem do outro, visto que se relaciona com o nosso próximo, fazendo o que é vantajoso a um outro" significando $\mathrm{o}$ ato de partilhar como uma preocupação com o outro além de si mesmo.

\section{Considerações finais}

É fundamental a análise comparativa dos dados, pois permite avaliar se as crianças foram capazes de aprender os conceitos de cada uma das virtudes trabalhadas e, além disso, se foram capazes de vivê-las. O fato de estarem em grupo, segundo explica Maritain (1966), foi indispensável e contribuiu para a compreensão de si próprio como um indivíduo ético e, ao mesmo tempo, pertencente ao meio social. O processo de formação do caráter é iniciado na infância e acontece por meio da contribuição de diversos fatores que devem ser constantemente avaliados. Os dois principais são a interação social e a prática de virtudes, tal como foi explicado. O ambiente escolar é propício a esse desenvolvimento em qualquer fase que a criança esteja. É fundamental, conforme a avaliação aqui apresentada, que o professor dê a importância devida à formação do caráter do aluno e ao papel fundamental que tem, enquanto é capaz de auxiliá-lo na aquisição e prática das virtudes.

A formação integral do aluno depende da formação do caráter. É preciso saber como tratar os outros por meio das virtudes, de maneira que a dignidade da pessoa seja reconhecida. A interação social contribui de forma positiva para esse 
desenvolvimento, como é mostrado neste artigo. O exercício da virtude permite o convívio com diferentes pessoas, tornando a criança capaz de lidar e conviver bem com essas em todas as situações, conforme nossa avaliação identificou. Essa interação, iniciada no ambiente familiar, pode ser desenvolvida com grande potencial na escola, por ser esse um ambiente pleno de diversidade. É primordial que a interação social comece nos primeiros anos de vida, a fim de garantir que a criança seja capaz de reconhecer o outro como diferente e digno de respeito, praticando a amizade, a honestidade e a justiça.

Foi possível avaliar como ocorrem o ensino/aprendizagem das virtudes, que acontecem, principalmente, pela observação da prática e com a oportunidade de exercitá-las. Não basta ensinar conceitos das virtudes, é preciso possibilitar a prática e, principalmente, favorecer o esforço das crianças em vivenciá-las. As crianças observam as práticas dos colegas e, essencialmente, dos adultos, que são modelos para elas e, então, os imitam.

Durante todo o processo, verificou-se que a criança, mesmo com pouca idade, é capaz de observar e identificar se a fala do professor é condizente com suas práticas. A partir disso, age da mesma forma com os colegas. Quando percebe que um colega foi elogiado pelo professor, pela virtude praticada, sente-se encorajado a imitar a prática elogiada. Por isso é importante que o professor tenha o hábito de afirmar as boas práticas que acontecem entre as crianças.

Foi possível avaliar a evolução das crianças em relação ao aprendizado e à prática das virtudes. Num primeiro momento, entenderam os significados de cada uma das virtudes trabalhadas, de acordo com o nível de sua capacidade cognitiva: amizade, honestidade e justiça. Em seguida apresentaram avanços na prática das virtudes, ainda que mantendo as limitações cognitivas próprias da faixa etária.

Concluiu-se que é possível avaliar como ocorre o início do processo de desenvolvimento do caráter da criança, que está relacionado à aprendizagem e à prática das virtudes. Há também conexão com o amadurecimento e com a capacidade de agir buscando o bem-estar do outro, quando isso lhe é ensinado. A capacidade de deixar de olhar apenas para si e entender que as próprias atitudes atingem diretamente a vida de outras pessoas foi avaliada como uma aquisição daquelas crianças. A criança, que está na fase de formação do caráter, pode pensar antes de ter atitudes precipitadas, que, de alguma maneira, prejudique alguém. As dinâmicas mostraram esse comportamento. A formação do caráter determina o agir do ser humano e o torna capaz de praticar diversas virtudes, mas é preciso que a construção tenha começado na infância. 
O professor precisa entender o poder que tem de modificar a realidade de um aluno, uma sala de aula ou mesmo uma escola, promovendo oportunidades para que pratiquem as virtudes. Lembrando que é um exemplo a ser seguido pelas crianças e por isso é responsável pela vivência de virtudes. Auxiliar na construção do caráter de uma criança é ajudar a construir uma sociedade mais ética e isto é uma possibilidade real.

A avaliação realizada e aqui descrita possibilitou as conclusões apresentadas, que impactam todos os membros da escola. Tanto as crianças quanto os professores são capazes de refletir sobre suas próprias atitudes e como essas influenciam significativamente no ambiente em que estão inseridos. Essa reflexão gera ação, que só acontece quando o processo de avaliação é feito de maneira eficaz. 


\title{
Evaluation of the process of character building of children in Early Childhood Education
}

\begin{abstract}
This paper deals with the possibility of assessing the beginning of the process of character building of children in early Childhood Education. Theoretical foundation is based on Aristotle's philosophy. Hypothesis is that social interaction and the practice of virtues should contribute to character building during daily school activities. The objectives of this research are: to improve learning and practicing of virtues (Friendship, Honesty and Justice); to contribute to social interaction; and to observe the connection between the practice of virtues and the process of socialization and beginning of character building by the children. Methodological approach was the Action Research method, with greater commitment, using observation, intervention, workshops and questionnaires. Activities specially created for this research were selected and presented to children. Results show that it is possible to assess the evolution of children's learning and practice of virtues and to help them begin the process of character building.
\end{abstract}

Keywords: Assessment. Character Building. Virtues. Early Childhood Education.

\section{Evaluación del inicio del proceso de formación del carácter de los niños en la Educación Infantil}

\section{Resumen}

Este articulo trata sobre la posibilidad de evaluar el inicio del proceso de formación del carácter de los niños en Educación Infantil. El fundamento teórico está en la filosofía de Aristóteles. La hipótesis es que la interacción social y la vivencia de virtudes pueden contribuir a esta formación durante las prácticas escolares diarias. Los objetivos de esta investigación son: promover el aprendizaje y la práctica de las virtudes de la amistad, la honestidad y la justicia; contribuir a la interacción social y observar la relación entre la práctica de las virtudes y el proceso de socialización y el inicio de la formación del carácter por parte de los niños. El enfoque metodológico fue la investigación-acción, con mayor compromiso, mediante observación, intervenciones, talleres y cuestionarios. Las actividades creadas especialmente para esta investigación fueron seleccionadas y presentadas a los niños. Los resultados muestran que es posible evaluar la evolución del aprendizaje y la práctica de virtudes en los niños y que es posible ayudarlos a iniciar el proceso de construcción del carácter.

Palabras clave: Evaluación. Formación del Carácter. Virtudes. Educación Infantil. 


\section{Referências}

ACHTMAN, A. 'They left everything and followed him": our response ability to ethical exemplars. In: HILDEBRAND SCHÜLERKREIS, 2017, Steubenville. Abstracts and papers. Steubenville:

Franciscan University of Steubenville, 2017. p. 1-10.

ALVES-MAZZOTTI, A. J. O método nas ciências sociais. In:

ALVES-MAZZOTTI, A. J.; GEWANDSZNAIDER, F. O método nas ciências naturais e sociais: pesquisa quantitativa qualitativa. 2. ed. São Paulo: Pioneira, 1998. p. 109-203.

ARENDT, H. Entre o passado e o futuro. São Paulo: Perspectiva, 1997.

ARISTÓTELES. Ética a Nicômaco. 4. ed. Bauru: Edipro, 2007.

AUSUBEL, D. P. Psicologia educacional. 2. ed. Rio de Janeiro: Interamericana, 1980.

BARDIN, L. Análise de conteúdo. Lisboa: Edições 70, 2010.

BARTHOLO, T. et al. What do children know upon entry to pre-school in Rio de Janeiro? Ensaio: Avaliação e Políticas Públicas em Educação, Rio de Janeiro, v. 28, n. 107, p. 292-313, abr./jun. 2020. https://doi.org/10.1590/s0104-40362019002702071

BENAVIDES-MORENO, N. et al. La gestión de los centros de educación parvularia en la Región del Maule (Chile): visiones desde la práctica educativa. Ensaio: Avaliação e Políticas Públicas em Educação, Rio de Janeiro, v. 27, n. 105, p. 881-903, out./dez. 2019. https://doi.org/10.1590/s0104-40362019002702009

BLOOM, P. O que nos faz bons ou maus. Rio de Janeiro: Best Seller, 2014.

BRUNER, J. S. O processo da educação. São Paulo: Companhia Nacional, 1978.

ERIKSON, E Identidade, juventude e crise. 2. ed. Rio de Janeiro: Guanabara, 1987.

ERIKSON, E. Infância e sociedade. 2. ed. Rio de Janeiro: Zahar, 1976.

FREUD, S. O ego e o Id. Rio de Janeiro: Imago, 1997.

HAVIGHURST, R. J. Human development and education. New York: Longmans, 1953. 
HILDEBRAND, D. Ethics. Chicago: Franciscan Herald, 1972.

HILDEBRAND, D. The art of living. Steubenville: Hildebrand, 2017.

HILDEBRAND, D. The nature of love. South Bend: St. Augustine, 2009.

LICKONA, T. What is a comprehensive approach to character education? [S. d.]. Disponível em: https://www2.cortland.edu/dotAsset/279703.pdf. Acesso em: 22 set. 2015.

LICKONA, T. What is effective character education? In: THE STONY BROOK SCHOOL SYMPOSIUM ON CHARACTER. 2001. Disponível em: http://www.mtsm.org/pdf/What $\% 20$ is $\% 20$ Effective $\% 20$ Character $\% 20$ Education.pdf Acesso em: 2 nov. 2017.

MACINTYRE, A. Depois da virtude: um estudo em teoria moral. Bauru: Edusc, 2004.

MAIA, M. V. C. M.; VIEIRA, C. N. M. Criatividade docente: Winnicott e a construção de subjetividades. Revista Subjetividades, Fortaleza, v. 16, p. 79-90, abr. 2016. http://dx.doi.org/10.5020/23590777.16.1.64-77

MARITAIN, J. Os direitos do homem e a lei natural. 3. ed. Rio de Janeiro: José Olympio, 1967.

MARITAIN, J. Rumos da educação. 4. ed. Rio de Janeiro: Agir, 1966.

MINAYO, M. C. S. Pesquisa social: teoria, método e criatividade. 18. ed. Petrópolis: Vozes, 2001.

MONTESSORI, M. The absorbent mind: a classic in education and child development for educators and parents. Henry Holt, 1967.

MORENO, J. L. Psicoterapia de grupo e psicodrama. São Paulo: Mestre Jou, 1974.

PIAGET, J. Estudos sociológicos. Rio de Janeiro: Forense, 1973.

PIAGET, J. O julgamento moral na criança. 4. ed. São Paulo: Summus, 1994.

PIAGET, J. O nascimento da inteligência na criança. Rio de Janerio: Zahar, 1971. (Coleção Plural, v. 10).

PIKUNAS, J. Human development, an emergent science. 3. ed. New York: MacGraw Hill, 1976. 
SCRIVEN, M. Avaliação: um guia de conceitos. Rio de Janeiro: Paz e Terra, 2018.

SUCUPIRA LINS, M. J. C. Ética se aprende na infância. Jornal Cátedra, Rio de Janeiro, Caderno 14, p. 3, 8 fev. 2004.

SUCUPIRA LINS, M. J. C. Método de pesquisa ação com maior comprometimento. Revista Eletrônica Pesquiseduca, Santos, v. 7, n. 13, p. 52-74, jan/jun, 2015.

SUCUPIRA LINS, M. J. C.; SOUZA, C. C. S. Avaliação do desenvolvimento da personalidade moral. Ensaio: Avaliação e Políticas Públicas em Educação, Rio de Janeiro, v. 26, n. 100, p. 1004-1020, jul./set. 2018. https://doi.org/10.1590/s0104-40362018002601402

Informações sobre as autoras

Bruna Rodrigues Cardoso Miranda: Doutoranda em Educação pela Universidade Federal do Rio de Janeiro. Pesquisadora e bolsista da Capes. Contato: rodriguesbrc@gmail.com iD https://orcid.org/0000-0002-8588-062X

Maria Judith Sucupira da Costa Lins: Doutora em Educação pela Universidade Federal do Rio de Janeiro. Professora Titular do Departamento de Fundamentos da Educação da Faculdade de Educação da mesma universidade. Contato: mariasucupiralins@terra.com.br iD https://orcid.org/0000-0001-5404-6061 